Zur jüngsten Reform des Europäischen Emissionshandels

\title{
Emissionshandel reloaded
}

\author{
Im September 2015 hat der Rat der Europäischen Union die \\ neueste Reform des Europäischen Emissionshandels gebilligt. \\ Ziel ist die Verknappung der Zertifikate, um den Preisverfall \\ umzukehren. Dieses richtige Signal kommt jedoch zu spät und \\ zu zögerlich. \\ Von Achim Lerch
}

m Wesentlichen geht es bei der Reform um die Einführung einer sogenannten Marktstabilitätsreserve zum 1. 1. 2019, in die Zertifikate automatisch eingestellt werden, wenn eine bestimmte Schwelle des Überhangs überschritten wird. Dadurch soll dem Preisverfall und dem daraus resultierenden Rückgang der Innovationsanreize entgegengewirkt werden. Auch die 900 Millionen Zertifikate, deren Versteigerung aus diesem Grund vom Zeitraum 2014 bis 2016 bereits auf den Zeitraum 2019 bis 2020 verschoben wurde, sollen in die Marktstabilitätsreserve fließen.

\section{Richtiges Signal, aber zu spät}

Die Verknappung ist das richtige Signal, das aber einerseits bereits zu Beginn der laufenden dritten Handelsperiode hätte gesetzt werden sollen und nun andererseits zügiger erfolgen müsste (Lerch/Rudolph 2013). Dies gilt auch, wenn der Starttermin 2019 bereits ein hart erkämpfter Erfolg des EU-Parlamentes gegenüber dem Europäischen Rat ist, der erst 2021 beginnen wollte.

Auch scheut man vor einer wirklich dauerhaften Verknappung der Zertifikate zurück: Für den Fall zu stark steigender Preise sind Rückführungen in den Markt, also Reserveverkäufe, geplant. Grundlage ist die Überprüfung der Marktstabilitätsreserve hinsichtlich ihrer Wirkung auf Wettbewerbsfähigkeit, Carbon Leakage, Wachstum und Beschäftigung. Diese Hintertür zur Begrenzung von Preisan- stiegen ist wohl ein Zugeständnis an die Industrie, die ihre Ablehnung der Reform bereits geäußert hat. Denn die Industrie befürchtet zunehmenden Druck auf die Wettbewerbsfähigkeit sowie Kostensteigerungen für die energieintensiven Unternehmen von bis zu fünf Milliarden Euro pro Jahr (Spiegel Online 2015).

\section{Verknüpfung statt Reserveverkäufe}

Unabhängig davon, ob die Preis- und Kostensteigerungen tatsächlich so hoch ausfallen, gäbe es zur Begrenzung des Preisanstieges eine Alternative zu den Reserveverkäufen, die ja auch die Emissionsmenge wieder erhöhen würden: ein konsequentes Vorantreiben der Verknüpfung des Europäischen Emissionshandels mit anderen Emissionshandelssystemen, vor allem in den USA. Eine solche Verknüpfung hätte, neben den Effizienzgewinnen, die folgenden Vorteile: Da die Preise in den USA zum Teil noch unter denen der EU liegen, würde über den Ausgleich der Zertifikatspreise der Preisanstieg in Europa trotz Verknappung und vor allem bei Beibehaltung der geplanten Emissionsminderung begrenzt. Gleichzeitig wären die Emittenten in den USA durch eine steigende Nachfrage nach Zertifikaten gezwungen, ihre eigenen Emissionsminderungen zu erhöhen. Dies wäre aus Gründen der ökologischen Effektivität begrüßenswert und würde angesichts der nach wie vor deutlich höheren Pro-Kopf-Emissio- nen in den USA auch zu mehr Verursachungsgerechtigkeit in der internationalen Klimapolitik führen (Lerch 2011). Zudem würde ein Argument der Kritiker des Emissionshandels entkräftet: Dass ein isoliertes europäisches Vorgehen in der Klimapolitik nur der europäischen Wirtschaft schade, ohne dem Klimaschutz zu nutzen, solange andere Großemittenten nicht mitziehen.

\section{Ausdehnung des Kohlenstoffmarktes}

Wie eine solche Verknüpfung funktionieren kann, hat jüngst die Verknüpfung des Emissionshandels in Kalifornien und Quebec gezeigt. Steigendes Potenzial für einen globalisierten KohlenstoffdioxidMarkt zeigen auch Bestrebungen in Washington State und Ontario, Emissionshandelssysteme $\mathrm{zu}$ etablieren und mit den existierenden zu verknüpfen.

Eine Ausdehnung des Kohlenstoffmarktes durch eine solche Verbindung häufig regionaler Systeme erscheint nach wie vor als ein vielversprechender Weg, der auch unabhängig von Klimaabkommen auf nationalstaatlicher Ebene gangbar ist.

\section{Literatur}

Lerch, A. (2011): $\mathrm{CO}_{2}$-Emissionshandel - effizient oder gerecht? In: Zeitschrift für Sozialökonomie 48. S. 39-47.

Lerch, A./Rudolph, S. (2013): Klimaschutz in Europa: Effektiv, effizient, gerecht? In: Ökologisches Wirtschaften 2/2013. S. 8-9.

Spiegel Online (2015): Emissionshandel: Europaparlament billigt Reform, Industrie grummelt. IM Internet unter: www.spiegel.de/wirtschaft/ soziales/klimaschutz-eu-parlament-billigtemissionshandel-reform-a-1042724.html

AUTOR + KONTAKT

Dr. Achim Lerch ist Professor für Allgemeine Volkswirtschaftslehre an der Hessischen Berufsakademie/University of Cooperative Education. E-Mail: achim.lerch@hessische-ba.de 